УДК 331.101 .52

$10.17213 / 2075-2067-2021-4-151-163$

\title{
РАЗРАБОТКА МЕТОДА ОЦЕНКИ ИЗМЕНЕНИЯ ЧЕЛОВЕЧЕСКОГО КАПИТАЛА В РЕЗУЛЬТАТЕ ПРОЦЕССОВ NВІС-КОНВЕРГЕНЦИИ И ПРИМЕНЕНИЯ СИСТЕМНОЙ ПАРАДИГМЫ
}

\author{
(C) 2021 г. А. А. Пахомова , Ш. Халас ${ }^{* *}$ А. А. Нардина" \\ "Южнно-Российский государственный политехнический университет (НПИ) \\ имени М. И. Платова, г. Новочеркасск, Россия \\ "Будапештский университет технологий и экономики, г. Будапешт, Венгрия
}

Целью исследования является обоснование необходимости разработки метода измерения человеческого капитала в условиях развития NBIC-конвергенции и применения системной парадигмы.

Методологическую базу исследования представляют теории «человеческого капитала» и различные методики его оценки. Применение этих методов позволило изучить сложившиеся тенденции и выделить основные характеристики, положительные и отрицательные стороны каждого из методов, возможности нивелировать их в условиях NBICконвергенции.

Результаты исследования. В результате выявлено, что несмотря на глубокий и разносторонний подход к оченке человеческого капитала, большинство ученых сходятся во мнении об аутентичности данной научной категории, ее емкости и многогранности, зависимости от множества факторов и не возможности, а скорее, целесообразности сохранения персонализачии и уникальности. Одним из важных результатов является вывод, что приращение человеческого капитала в условиях NBIC-конвергенции целиком и полностью происходит в процессе образования, повышения квалификации и в прочессе трудовой деятельности в мультипространственных производственных системах. Интенсификация роста человеческого капитала происходит по мере потребления, совершенствования и расширения квалификационных способностей, при этом качественной трансформации подвергается и сам субъект. Наблюдается закономерный прочесс интенсификации роста человеческого капитала в результате повышения его квалификационных способностей в мультипространственных производственных системах и, как следствие, потреблении им продуктов NBIC-конвергенции.

Перспективу исследования составляет развитие системной парадигмы Яноша Корнаи - фундаментальная основа создания производственных и технических систем в условиях NBIC-конвергенции.

Ключевые слова: NBIC-конвергенция; системная парадигма; технологии; наука; человек; человеческий капитал.

1 Исследование выполнено при финансовой поддержке РФФИ и РЯИК в рамках научного проекта 20-510-23002 «Развитие системной парадигмы Яноша Корнаи - фундаментальная основа создания производственных и технических систем в условиях NBIC-конвергенции». 


\title{
DEVELOPMENT OF A METHOD \\ FOR ASSESSING CHANGES IN HUMAN CAPITAL AS A RESULT OF NBIC CONVERGENCE PROCESSES AND THE APPLICATION OF THE SYSTEM PARADIGM
}

\author{
(C) 2021 A. A. Pakhomova, S. Halasz **, A. A. Nardina*
}

\section{"Platov South Russian State Polytechnic University (NPI), Novocherkassk, Russia **Budapest University of Technology and Economics, Budapest, Hungary}

The purpose of the study is to substantiate the need to develop a method for measuring human capital in the context of the development of NBIC convergence and the application of the system paradigm.

The methodological basis of the research is represented by the theories of "human capital», and various methods of its assessment. The use of these methods made it possible to study the current trends and identify the main characteristics, positive and negative aspects of each of the methods, the possibility of leveling them in the conditions of NBIC convergence.

The results of the study. As a result, it is revealed that despite a deep and versatile approach to the assessment of human capital, most scientists agree on the authenticity of this scientific category, its capacity, and versatility, depending on many factors and not the possibility, but rather the expediency of preserving personalization and uniqueness. One of the important results is the conclusion that the increment of human capital in the conditions of NBIC convergence occurs entirely in the process of education, professional development and in the process of working activity in multi-spatial production systems. The intensification of the growth of human capital occurs as the consumption, improvement and expansion of qualification abilities, while the subject itself undergoes a qualitative transformation. There is a natural process of intensification of the growth of human capital as a result of increasing its qualification abilities in multi-dimensional production systems and, as a result, its consumption of NBIC convergence products.

The prospect of the study is the development of the Janos Kornai system paradigm the fundamental basis for creating production and technical systems in the conditions of NBIC convergence.

Key words: NBIC-convergence; system paradigm; technologies; science; human; human capital.

Введение. Проблема оценки человеческого капитала стала в экономической науке центральным звеном изучения последние более чем 200 лет [3]. Усиливает интерес к данной проблематике достижение науки и техники, ключевым звеном которого в настоящее время является NBIC-конвергенция. NBIC-конвергенция в современном мире науки является траекторией развития технологических укладов и перехода на 6 уровень [4].

Влияние наук в рамках NBIC-конвергенции не ограничивается односторонним воздействием, создает синергический эф- фект, что обусловлено получением результата не в одной стационарной отрасли знания, а получением сверхрезультата в области межнаучного пространства [9]. NBIC-конвергенция позволяет работать в межнаучном пространстве, получая синергетические результаты, усиленные самой конвергенцией науки. Таким образом, можно говорить о научных результатах, имеющих надотраслевой характер (Технологии шестого большого цикла Н. Кондратьева), что в свою очередь является основой для дальнейшего научно-технического прогресса и внедрения его результатов 
в производственные системы экономики [8]. Преобразования происходят внутри всех составляющих производственной системы, в том числе носителя трудовых ресурсов, тем более, большому изменению подвержен человеческий капитал.

Человеческий капитал становится неотьемлемой составляющей NBIC-конвергенции. Созданная благодаря человеку инновационная инфраструктура определяет качественное и количественное развития NBIC-технологии, опосредующих формирование и использование инновационного потенциала и проявление инновационной активности. NBIC-конвергенция позволяет продолжать развитие научно-технического прогресса по пути количественных преобразований в качественные, но на рубеже перехода на новый технологический уровень эволюционируют не отдельные технологии, а целые производственные системы, полностью динамично меняя свой состав [11]. В то же время качественное увеличение человеческого и социального капитала в результате процессов NBIC-конвергенции является фундаментальной основой динамичной и устойчивой траектории развития народного хозяйства страны.

Дефиниция «человеческий капитал» всегда представляла собой производственный фактор, в таком ракурсе понятие «человеческий капитал» в экономике было использовано в 1897 году Ирвином Фишером. Основные этапы развития теории человеческого капитала нами представлены в таблице 1.

В мировой научной мысли можно выделить работы Т. Шульца, С. Беккера Гэри, Н. Бонтиса, Э.Д. Долана и других авторов, внесших значительный вклад в развитие теории человеческого капитала. В отечественной науке проблематика человеческого капитала исследуется наиболее активно со второй половины XX века. Н. Римашевская выделяет «человеческий капитал» как «интегральную сумму таких составляющих, как здоровье, знание, культура и свобода личности». Р. М. Нуреев, Ю. В. Латов в работе «Человеческий и социальный капитал как основа современной экономики» дают следующие определение: «...человеческий капитал - это специфическая форма капитала, воплощенного в самом человеке, это имеющийся у че- ловека запас здоровья, знаний, навыков, способностей, мотиваций, которые содействуют росту его производительности труда и приносят ему доход в форме заработной платы или ренты». В своем исследовании мы опираемся на исследования предшественников, разделяя и поддерживая их научные результаты. В наших исследованиях «человеческий капитал», результатом которого является получение личностных и общественных благ, представляет собой совокупность элементов, необходимых для эффективной профессиональной деятельности, включающих знания, умения, навыки, опыт, здоровье, мотивацию. Классическая концепция человеческого капитала базируется на трех основных составляющих: «инвестиции в образование - развитие человеческого капитала - экономический рост и социальное развитие». Развитие «человеческого капитала» - закономерный ответ экономической науки и практики на факторы и современное состояние мировых экономических систем.

В рамках нашего исследования целесообразно выделить следующие особенности человеческого капитала:

1) человеческий капитал персонализирован, имеет высокую долю зависимости от инвестиций в него, дифференцирован в различные жизненные периоды;

2) имеет ограниченный непредсказуемый временной интервал использования;

3) полнота реализации зависит как от внутренних, так и от внешних факторов;

4) высокая зависимость от инфраструктуры как экономической, так и социальной;

5) не имеет амортизации, но в то же время человеческий капитал может нарастать в течение всей жизни человека так же, как и обесцениваться или истончаться;

6) возможность нереализации потенциала компетенции в форме знаний, способностей, рабочих и управленческих навыков;

7) бесконечное пополнение «копилки человеческого капитала»;

8) невозможность приобретения и отчуждения.

Истории изучения феномена человеческого капитала не одну сотню лет. Существуют различные модели и теории оценки человеческого капитала, основные ключевые элементы представлены в таблице 2. Традиционно вы- 
«Человеческий капитал» как ключевая дефиниция исследования

\begin{tabular}{|c|c|}
\hline Автор & Основополагающий элемент \\
\hline У. Петти & $\begin{array}{l}\text { Материальной базой достатка служат земля и ресурсы природы, основным } \\
\text { источником накопления общественного богатства является включенный } \\
\text { в материальное производство живой труд (т.е. труд работника) [16] }\end{array}$ \\
\hline К. Макс & $\begin{array}{l}\text { Труд как созидатель потребительных стоимостей, как полезный труд, есть } \\
\text { не зависимое от всяких общественных форм условие существования людей, } \\
\text { вечная, естественная необходимость: без него не был бы возможен обмен } \\
\text { между человеком и природой, то есть не была бы возможна сама человечес- } \\
\text { кая жизнь [14] }\end{array}$ \\
\hline Ф. Кенэ & $\begin{array}{l}\text { Без приложения труда человека земли сами по себе не представляют никакой } \\
\text { ценности [11] }\end{array}$ \\
\hline А. Смит & $\begin{array}{l}\text { Увеличение производительности полезного труда зависит, прежде всего, } \\
\text { от повышения ловкости и умения рабочего, а затем от улучшения машин } \\
\text { и инструментов, с помощью которых он работает [17] }\end{array}$ \\
\hline Дж. С. Милль & $\begin{array}{l}\text { Само человеческое существо ... не является капиталом. Человек служит це- } \\
\text { лью, ради которой богатство существует. Но его приобретенные способнос- } \\
\text { ти, выступающие только как средство и реализующиеся только посредством } \\
\text { труда, с полным основанием можно отнести к категории капитала [23] }\end{array}$ \\
\hline Н. Сениор & $\begin{array}{l}\text { Человек - это капитал с затратами на его содержание с ожиданием получе- } \\
\text { ния выгоды в будущем [24] }\end{array}$ \\
\hline Т. Шульц & $\begin{array}{l}\text { Первым вводит в научный оборот формулировку понятия человеческого ка- } \\
\text { питала как фактора производств [25] }\end{array}$ \\
\hline Ф. Фукуяма & $\begin{array}{l}\text { В структуру капитала включает «знания и квалификацию людей», подчерки- } \\
\text { вая, что «значение этих факторов во временном разрезе постоянно возраста- } \\
\text { ет» [19] }\end{array}$ \\
\hline $\begin{array}{l}\text { Л. Эдвинсон } \\
\text { и М. Мэлоун }\end{array}$ & $\begin{array}{l}\text { Человеческий капитал следует понимать как «совокупность знаний, практи- } \\
\text { ческих навыков, творческих способностей сотрудников, вовлеченных к вы- } \\
\text { полнению текущих задач, а также устоявшиеся в компании “моральные цен- } \\
\text { ности”, культура труда и общий подход к делу» [22] }\end{array}$ \\
\hline $\begin{array}{l}\text { К. Р. Макко- } \\
\text { нелл и } \\
\text { С. Л. Брю }\end{array}$ & $\begin{array}{l}\text { «Накопление предшествующих вложений в образование, подготовку, здра- } \\
\text { воохранение и другие факторы, способствующие повышению производи- } \\
\text { тельности труда» [13] }\end{array}$ \\
\hline $\begin{array}{l}\text { Н. Г. Черны- } \\
\text { шевский }\end{array}$ & $\begin{array}{l}\text { «...ни один из элементов успешности производства не имеет такого громад- } \\
\text { ного значения, как степень умственного развития работника; климат, поч- } \\
\text { ва, запасы капитала, самая крепость физических сил, - все это ничтожно } \\
\text { по сравнению с развитием мысли» [21] }\end{array}$ \\
\hline С. А. Дятлов & $\begin{array}{l}\text { «...человеческий капитал есть сформированный в результате инвестиций } \\
\text { и накопленный человеком запас здоровья, навыков, способностей, знаний, } \\
\text { мотиваций, которые целесообразно используются в той или иной сфере об- } \\
\text { щественного воспроизводства, содействуют росту производительности труда } \\
\text { и производства и тем самым влияют на рост доходов данного человека...» [7] }\end{array}$ \\
\hline
\end{tabular}


Окончание таблицы 1

\begin{tabular}{|c|c|}
\hline М. М. Хайкин & $\begin{array}{l}\text { «...особый вид капитала, который при определенных специфических усло- } \\
\text { виях может приобретать иррациональную форму...» [20] }\end{array}$ \\
\hline $\begin{array}{l}\text { Ю. А. Корча- } \\
\text { гин }\end{array}$ & $\begin{array}{l}\text { «...интенсивный синтетический и сложный производительный фактор раз- } \\
\text { вития экономики и общества, включающий креативные трудовые ресурсы, } \\
\text { инновационную систему, высокопроизводительные накопленные знания, } \\
\text { системы обеспечения профессиональной информацией, инструменты ин- } \\
\text { теллектуального и организационного труда, качества жизни и интеллекту- } \\
\text { альной деятельности, обеспечивающие эффективное функционирование } \\
\text { человеческого капитала...» [10] }\end{array}$ \\
\hline $\begin{array}{l}\text { Л. И. Абал- } \\
\text { кина }\end{array}$ & $\begin{array}{l}\text { «...сумма врожденных способностей, общего и специального образования, } \\
\text { приобретенного профессионального опыта, творческого потенциала, мо- } \\
\text { рально-психологического и физического здоровья, мотивов деятельности, } \\
\text { обеспечивающих возможность приносить доход...» [2] }\end{array}$ \\
\hline И. В. Грузков & $\begin{array}{l}\text { «...экономические отношения людей по поводу сформированной и накап- } \\
\text { ливаемой в течение жизни совокупности биологических, социальных, ду- } \\
\text { ховных производительных и профессиональных характеристик человека, } \\
\text { технологий их использования в хозяйственной деятельности с целью повы- } \\
\text { шения эффективности труда и получения материального дохода или мораль- } \\
\text { ного вознаграждения работника...» [5] }\end{array}$ \\
\hline Л. Н. Салимов & $\begin{array}{l}\text { «...специфической ценностью, представленной системой постоянно разви- } \\
\text { вающихся, созидательно ориентированных и востребованных человечес- } \\
\text { ких свойств, обеспечивающих расширенное воспроизводство жизненных } \\
\text { благ...» [18] }\end{array}$ \\
\hline
\end{tabular}

деляют стоимостной, полезности, индексный подход и методику Всемирного банка. В рамках исследования целесообразно выделить измерение человеческого капитала на основе оценки прошлых усилий, на основе оценки отдачи (результата), оценки человеческого капитала в разных стадиях воспроизводства.

Несмотря на глубокий и разносторонний подход к оценке человеческого капитала, большинство ученых сходятся во мнении об аутентичности данной научной категории, ее емкости и многогранности, зависимости от множества факторов и невозможности, а скорее, целесообразности сохранения персонализации и уникальности. Необходимо признать, что количественный подход имеет низкую достоверность результатов. Среди современных методов оценки доминируют те, в которых затраты на формирование человеческого капитала имеют вид издержек, а получаемые блага от его функционирова- ния выражаются через доходы. Установлено, что в настоящее время методики оценки человеческого капитала статистических служб развитых стран исходят из узкого определения человеческого капитала и в целях достижения сопоставимости различных его элементов в расчетах оперируют главным образом стоимостными величинами. Оппоненты подобного подхода справедливо указывают на то, что сложность и комплексность категории человеческого капитала не может быть выражена через количественные показатели. Приращение человеческого капитала в условиях NBIC-конвергенции целиком и полностью происходит в процессе образования, повышения квалификации и в процессе трудовой деятельности в мультипространственных производственных системах. Интенсификация роста человеческого капитала при применении системной парадигмы происходит по мере потребления и развития квали- 


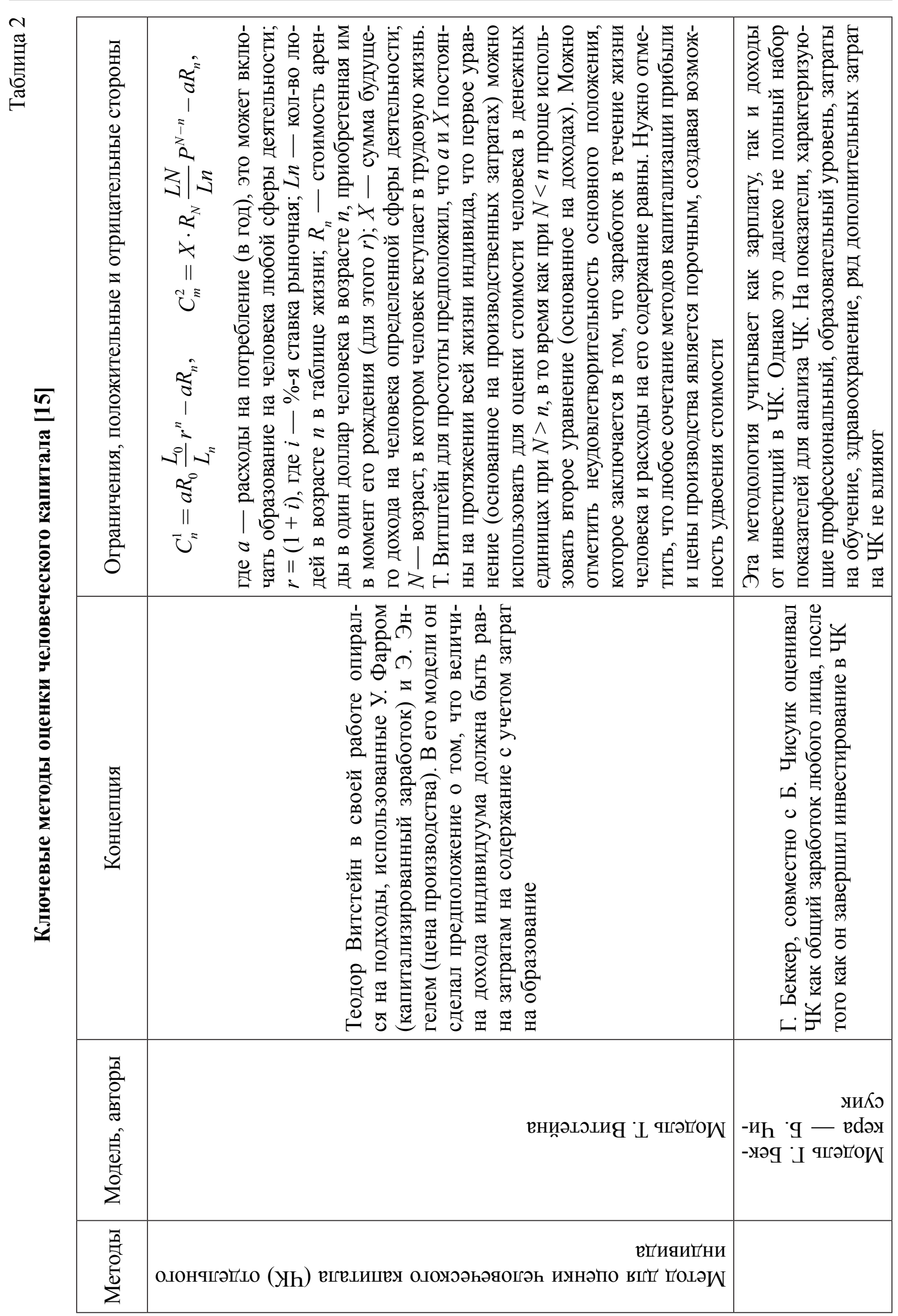




\begin{tabular}{|c|c|c|}
\hline 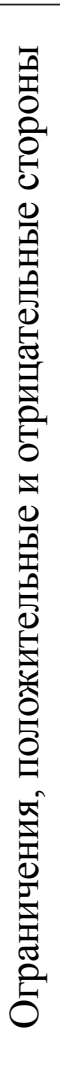 & 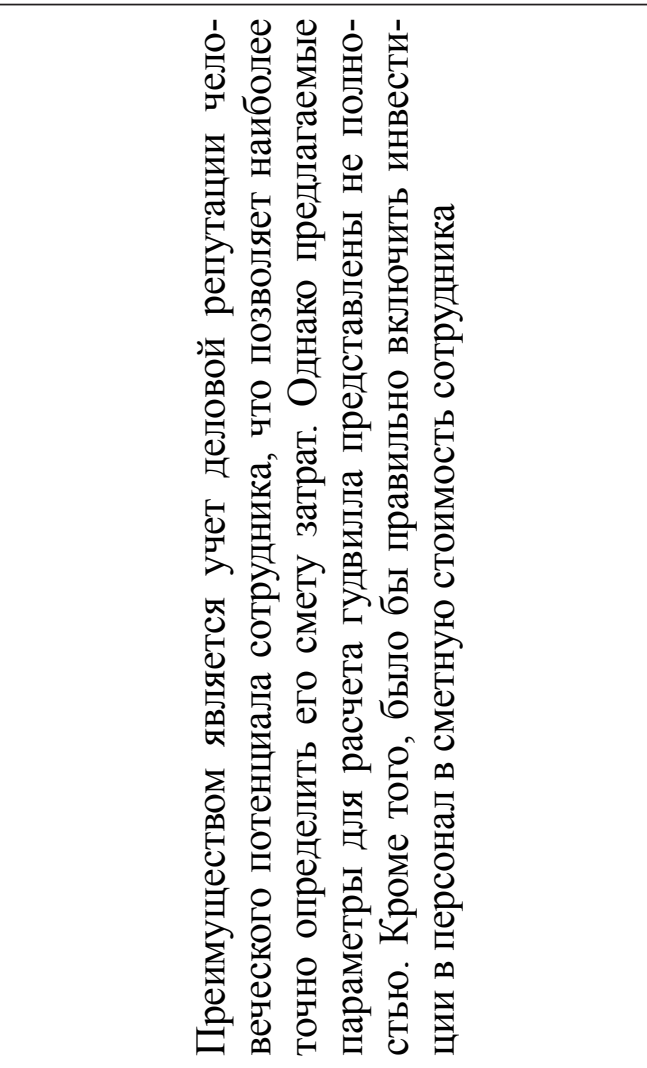 &  \\
\hline 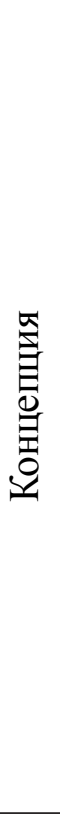 & 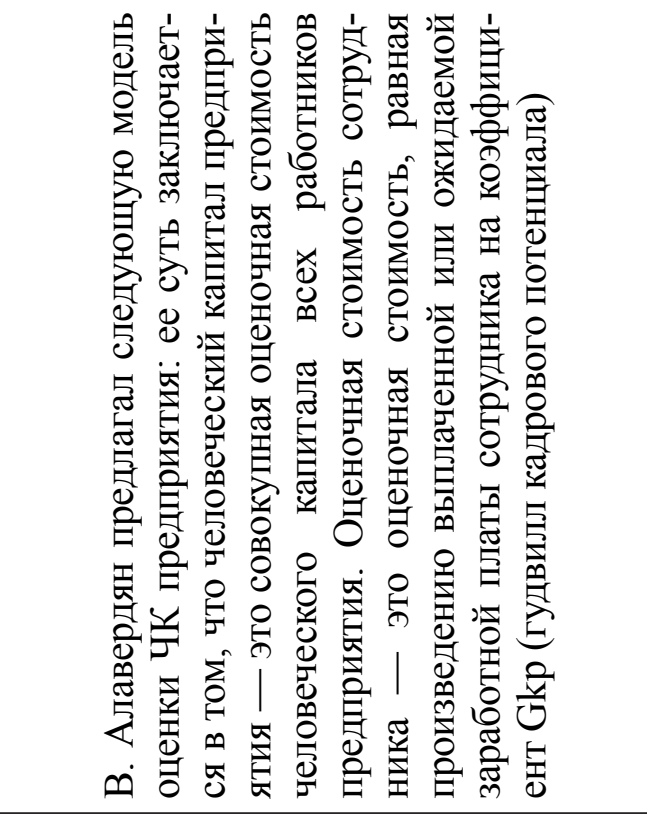 & 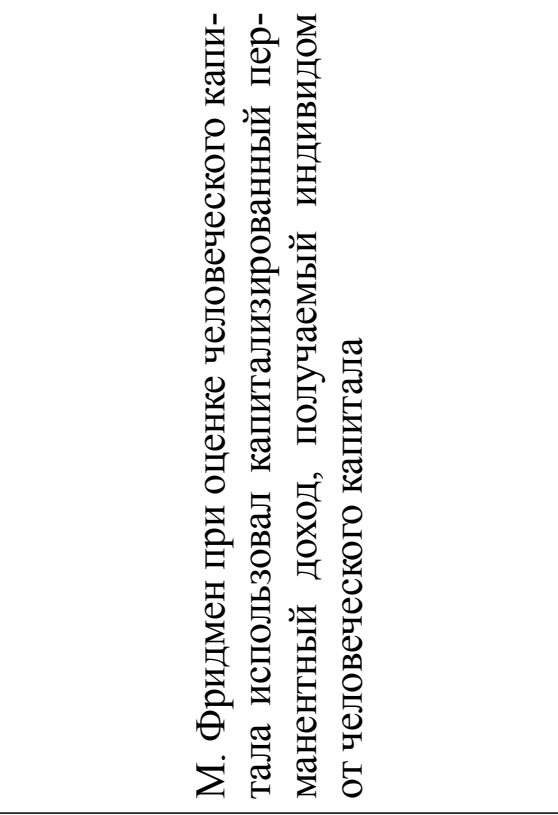 \\
\hline 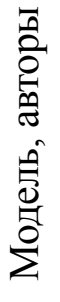 & 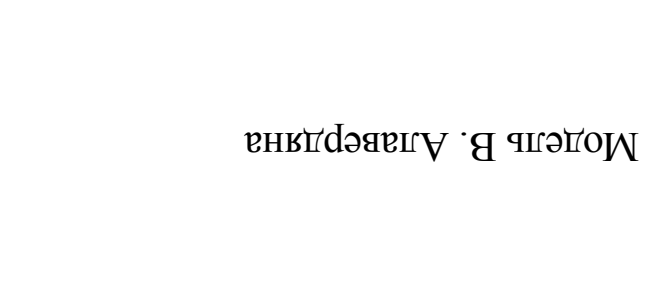 & внәш \\
\hline 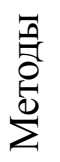 & 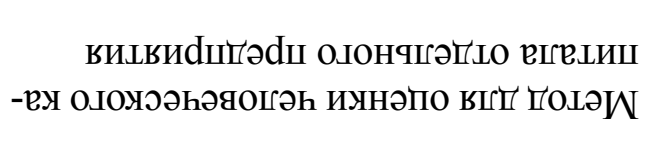 & \\
\hline
\end{tabular}




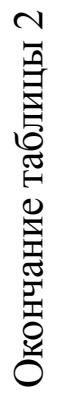

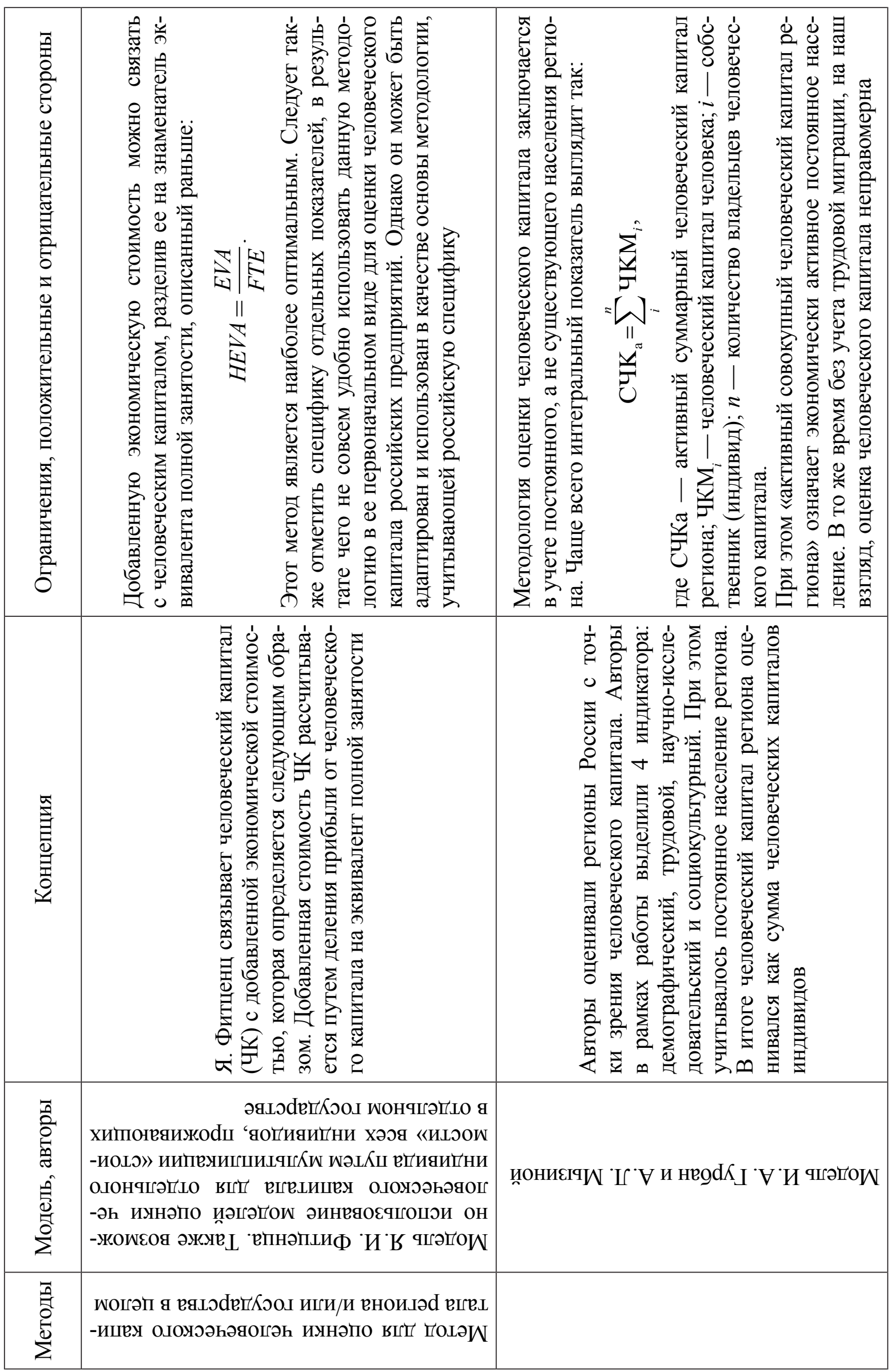


фикационных способностей, качественной трансформации подвергается и сам субъект. Наблюдается закономерный процесс увеличения человеческого капитала в результате повышения его квалификационных способностей (ценностных установок его компетенций) и, как следствие, приобретения им продуктов NBIC-конвергенции.

Заключение. Центральным звеном NBIC-конвергенции является человек со всем его уникальным составом. Многогранность и многоаспектность центральных понятий данной научной работы усиливают и дополняют друг друга. Более того, можно с уверенностью говорить об устойчивых взаимозависимых связях данных понятий. NBIC-конвергенция приводит к глубокой трансформации сущности как «человека», так и «человеческого капитала». Фундаментальные технологические прорывы NBIC-конвергенции базируются на человеческом капитале и достижении НТП, в то же время приводят к многократному росту человеческого капитала, имея синергический эффект. Проведенный анализ существующих методов оценки данной категории показал устойчивую зависимость системы показателей, включающей блоки образования, здоровья, уровень дохода как самого индивида, так и организации, региона, страны и тп. Основные звенья и появляющиеся на стыке междисциплинарных направлений оказывают непосредственное влияние и направлены главным образом на увеличение качества жизни человека, включая основные первоначальные показатели оценки.

Исследования показали, что методы оценки изменения человеческого капитала в результате процессов NBIC-конвергенции и применения системной парадигмы возможны на условиях комплексного и синтезирующего подхода к существующим методам, что позволяет не только адаптировать и минимизировать отрицательные стороны каждого из отдельных подходов, но и перейти к стратегическому управлению ключевой дефиниции. Системная парадигма является ключевым элементом развития экономики, базирующейся на результатах NBIC-конвергенции, в основе которой заложено «повышение производительности человека» [26].

\section{Литература}

1. Научный проект 20-510-23002 «Развитие системной парадигмы Яноша Корнаи - фундаментальная основа создания производственных и технических систем в условиях NBICконвергенции» [Электронный ресурс]. — Peжим доступа: https://kias.rfbr.ru/index.php.

2. Абалкина Л.И. Стратегический ответ России на вызовы нового века. - М.: Издательство «Экзамен», 2004. - 605 с.

3. Абалкин Л. И. Экономическая энциклопедия. - М.: Экономика, 2009.

4. Акаев А., Рудской А. Синергетический эффект NBIC-технологий и мировой экономический рост в первой половине XXI века // Экономическая политика. - 2014. - №2. C. 25-46.

5. Грузков И.В. Воспроизводство человеческого капитала в условиях формирования инновационной экономики России: теория, методология, управление: монография / И. В. Грузков; науч. ред. В.И. Бережной. М.: Экономика, 2013. - 384 с.

6. Дудин М.Н., Шутьков А.А., Анищен$\kappa о$ A.H. Шестой большой цикл в развитии мировой экономики: эпоха NBIC-конвергенции в АПК [Электронный ресурс]. - Peжим доступа: http:/www.ipr-ras.ru/old_site/ articles/2019-03-74-82-dudin.pdf.

7. Дятлов С.А. Теория человеческого капитала / С.А. Дятлов. - СПб.: СПбУЭФ, 1995. - $160 \mathrm{c}$.

8. Колбачев Е.Б. Технологические уклады и инструментарий управления инновациями // Научно-технические ведомости СанктПетербургского политехнического университета. Экономические науки. - 2010. №4. - C. 116-122.

9. Конвергенция технологий - новая детерминанта развития общества [Электронный ресурс]. - Режим доступа: http:// transhumanism-russia.ru/content/view/621/.

10. Корчагин Ю.А. Человеческий капитал - интенсивный социально-экономический фактор развития личности, экономики, общества и государственности [Электронный ресурс] / Ю.А. Корчагин. - Режим доступа: http://psy.hse.ru/orgps/humancapital (Дата обращения: 06.07.2021).

11. Кенэ $Ф$. Избранные экономические произведения / Ф. Кенэ. - М.: Издательс- 
тво социально-экономической литературы, 1960. - 552 c.

12. Ленчук Е.Б. Задачи по созданию условий для перехода российской экономики на инновационный путь развития [Электронный ресурс] // Политическое образование. — 28.04.2010. — Режим доступа: http:// www.lawinrussia.ru/zadachi-po-sozdaniyuuslovii-dlya-perekhoda-rossiiskoi-ekonomikina-innovatsionnyi-put-razvitiya.

13. Макконелл К.Р. Экономика: принципы, проблемы и политика: в 2 т. / К. Р. Макконелл, С. Л. Брю. - М.: Республика, 1992. T. 2. $-400 \mathrm{c}$.

14. Маркс K. Капитал. Критика политической экономии: в 3 т. / К. Маркс, Ф. Энгельс; пер. И. И. Степанова-Скворцова. - М.: Политиздат, 1955. - Т. II. - Кн. II: Процесс обращения капитала. - 530 с.

15. Парушина Н. В., Льттнева Н. А., Семиделихин $E$. A. Методы измерения и оценки человеческого капитала (научный обзор) [Электронный ресурс]. — Режим доступа: https:// science-economy.ru/ru/article/view?id=912.

16. Петти У. Экономические и статистические работы / У. Петти. - М.: Соцэкгиз, 1940. - $324 \mathrm{c}$.

17. Смит A. Исследование о природе и причинах богатства народов / А. Смит. М.: Соцэкгиз, 1962. - 686 с.

18. Салимов Л. Н. Основы экономической теории человеческого капитала: методологические и институциональные аспекты. - Казань: Фэн, 2007.

19. Фукуяма Ф. Доверие. Социальные добродетели и путь к процветанию: пер. с англ. / Ф. Фукуяма. — М.: АСТ, 2004. $730 \mathrm{c}$.

20. Хайкин М. М. Эволюция теории человеческого капитала [Электронный ресурс]/ M.M. Хайкин. - Режим доступа: http:// alternativy.ru/ru/webfm_send/724 (Дата обращения: 26.06.2021).

21. Чернышиевский Н.Г. Избранные экономические произведения / Н.Г. Чернышевский. - М.: Политиздат, 1948. — 759 с.

22. Эдвинссон Л. Интеллектуальный капитал. Определение истинной стоимости компании / Л. Эдвинссон, М. Мэлоун // Новая постиндустриальная волна на Западе. Антология / под ред. В.Л. Иноземцева. - М.: Academia, 1999. - С. 432-447.
23. Mill J. Principles of Political Economy. With some of their applications to social philosophy / J. Mill. — Longmans, Green, Reader, and Dyer, $1876 .-643$ p.

24. Senior N.W. An Outline of the Science of Political Economy / N.W. Senior. - N. Y.: Kelley, 1965. - 249 p.

25. Schultz T.W. Capital Formation by Education / T. W. Schultz // Journal of Political Economy. - 1960. — Vol. 68. - Pp. 571-583.

26. Roco Mihail C. Coherence and Divergence of Megatrends in Science and Technology. In Converging Technologies for Improving $\mathrm{Hu}-$ man Performance: Nanotechnology, Biotechnology, Information Technology and the Cognitive Science / ed. Mihail C. Roco and William S. Arlington, VA: National Science Foundation, 2002.

\section{References}

1. Nauchnyj proekt 20-510-23002 «Razvitie sistemnoj paradigmy Janosha Kornai fundamental'naja osnova sozdanija proizvodstvennyh i tehnicheskih sistem v uslovijah NBICkonvergencii» [Scientific project 20-510-23002 «Development of the system paradigm of Janos Kornai - the fundamental basis for creating production and technical systems in the conditions of NBIC convergence»] [Jelektronnyj resurs]. — URL: https://kias.rfbr.ru/index.php.

2. Abalkina L.I. Strategicheskij otvet Rossii na vyzovy novogo veka [Russia's strategic response to the challenges of the new century]. - Moscow: Izdatel'stvo «Jekzamen», 2004. - $605 \mathrm{p}$.

3. Abalkin L.I. Jekonomicheskaja jenciklopedija [Economic Encyclopedia]. - Moscow: Jekonomika, 2009.

4. Akaev A., Rudskoj A. Sinergeticheskij jeffekt NBIC-tehnologij i mirovoj jekonomicheskij rost $\mathrm{v}$ pervoj polovine XXI veka [Synergetic effect of NBIC technologies and world economic growth in the first half of the XXI century] // Jekonomicheskaja politika [Economic policy]. 2014. — №2. - Pp. 25-46.

5. Gruzkov I. V. Vosproizvodstvo chelovecheskogo kapitala $\mathrm{v}$ uslovijah formirovanija innovacionnoj jekonomiki Rossii: teorija, metodologija, upravlenie: monografija [Reproduction of human capital in the conditions of the formation of the innovative economy of Rus- 
sia: theory, methodology, management: monograph]/ I. V. Gruzkov; nauch. red. V.I. Berezhnoj [I.V. Gruzkov; in V.I. Berezhnoy (eds.)]. Moscow: Jekonomika, 2013. - 384 p.

6. Dudin M.N., Shut'kov A. A., Anishhenko $A$. N. Shestoj bol'shoj cikl v razvitii mirovoj jekonomiki: jepoha NBIC-konvergencii $\mathrm{v}$ APK [The sixth big cycle in the development of the world economy: the era of NBIC convergence in the agro-industrial complex] [Jelektronnyj resurs]. — URL: http://www.ipr-ras.ru/old_ site/articles/2019-03-74-82-dudin.pdf.

7. Djatlov S.A. Teorija chelovecheskogo kapitala [Theory of human capital] / S. A. Djatlov. - Saint Petersburg: SPbUJeF, 1995. $160 \mathrm{p}$.

8. Kolbachev E. B. Tehnologicheskie uklady $\mathrm{i}$ instrumentarij upravlenija innovacijami [Technological structures and tools for innovation management] // Nauchno-tehnicheskie vedomosti Sankt-Peterburgskogo politehnicheskogo universiteta. Jekonomicheskie nauki [Scientific and Technical News of St. Petersburg Polytechnic University. Economic sciences]. — 2010. №4. - Pp. 116-122.

9. Konvergencija tehnologij - novaja determinanta razvitija obshhestva [Convergence of technologies - a new determinant of the development of society] [Jelektronnyj resurs]. URL: http://transhumanism-russia.ru/content/ view/621/.

10. Korchagin Ju. A. Chelovecheskij kapital — intensivnyj social'no-jekonomicheskij faktor razvitija lichnosti, jekonomiki, obshhestva i gosudarstvennosti [Human capital - an intensive socio-economic factor in the development of personality, economy, society and statehood] [Jelektronnyj resurs] / Ju. A. Korchagin. - URL: http://psy.hse.ru/orgps/humancapital (Date accessed: 06.07.2021).

11. Kenje F. Izbrannye jekonomicheskie proizvedenija [Selected economic works] / F. Kenje. - Moscow: Izdatel'stvo social'nojekonomicheskoj literatury, 1960. - 552 p.

12. Lenchuk E. B. Zadachi po sozdaniju uslovij dlja perehoda rossijskoj jekonomiki na innovacionnyj put' razvitija [Tasks for creating conditions for the transition of the Russian economy to an innovative path of development] [Jelektronnyj resurs] // Politicheskoe obrazovanie. 28.04.2010. — URL: http:/www.lawinrussia.ru/ zadachi-po-sozdaniyu-uslovii-dlya-perekhoda- rossiiskoi-ekonomiki-na-innovatsionnyi-putrazvitiya.

13. Makkonell K.R. Jekonomika: principy, problemy i politika: $v 2$ t. [Economics: principles, problems and politics: in 2 volumes] / K.R. Makkonell, S.L. Brju. - Moscow: Respublika, 1992. - Vol. 2. - 400 p.

14. Marks K. Kapital. Kritika politicheskoj jekonomii: $v 3$ t. [Criticism of political economy: in 3 volumes] / K. Marks, F. Jengel's; per. I. I. Stepanova-Skvorcova. - Moscow: Politizdat, 1955. — Vol. II. — Book II: Process obrashhenija kapitala. $-530 \mathrm{p}$.

15. Parushina N.V., Lytneva N.A., Semidelihin E.A. Metody izmerenija i ocenki chelovecheskogo kapitala (nauchnyj obzor) Methods of measuring and evaluating human capital (scientific review)] [Jelektronnyj resurs]. — URL: https://science-economy.ru/ru/ article/view?id=912.

16. Petti U. Jekonomicheskie i statisticheskie raboty [Economic and statistical works] / U. Petti. - Moscow: Socjekgiz, 1940. — 324 p.

17. Smit A. Issledovanie o prirode i prichinah bogatstva narodov [Research on the nature and causes of the wealth of peoples] / A. Smit. Moscow: Socjekgiz, 1962. - $686 \mathrm{p}$.

18. Salimov L. N. Osnovy jekonomicheskoj teorii chelovecheskogo kapitala: metodologicheskie $\mathrm{i}$ institucional'nye aspekty [Fundamentals of the economic theory of human capital: methodological and institutional aspects]. Kazan': Fjen, 2007.

19. Fukujama F. Doverie. Social'nye dobrodeteli i put' $\mathrm{k}$ procvetaniju: per. s angl. [Trust. Social virtues and the path to prosperity: translated from English] / F. Fukujama. - Moscow: AST, 2004. - $730 \mathrm{p}$.

20. Hajkin M.M. Jevoljucija teorii chelovecheskogo kapitala [Evolution of the theory of human capital] [Jelektronnyj resurs] / M. M. Hajkin. — URL: http://alternativy.ru/ru/ webfm send/724 (Date accessed: 26.06.2021).

21. Chernyshevskij N.G. Izbrannye jekonomicheskie proizvedenija [Selected economic works] / N.G. Chernyshevskij. - Moscow: Politizdat, 1948. - 759 p.

22. Jedvinsson L. Intellektual'nyj kapital. Opredelenie istinnoj stoimosti kompanii [Intellectual capital. Determining the true value of a company] / L. Jedvinsson, M. Mjeloun // Novaja postindustrial'naja volna na Zapade. An- 
tologija [The new post-industrial wave in the West. Anthology] / pod red. V.L. Inozemceva [in V.L. Inozemtsev (eds.)]. - Moscow: Academia, 1999. - Pp. 432-447.

23. Mill J. Principles of Political Economy. With some of their applications to social philosophy / J. Mill. - Longmans, Green, Reader, and Dyer, 1876. - $643 \mathrm{p}$.

24. Senior N. W. An Outline of the Science of Political Economy / N.W. Senior. - N. Y.: Kelley, 1965. - 249 p.
25. Schultz T. W. Capital Formation by Education / T. W. Schultz // Journal of Political Economy. - 1960. - Vol. 68. - Pp. 571-583.

26. Roco Mihail C. Coherence and Divergence of Megatrends in Science and Technology. In Converging Technologies for Improving Human Performance: Nanotechnology, Biotechnology, Information Technology and the Cognitive Science / ed. Mihail C. Roco and William S. Arlington, VA: National Science Foundation, 2002 .

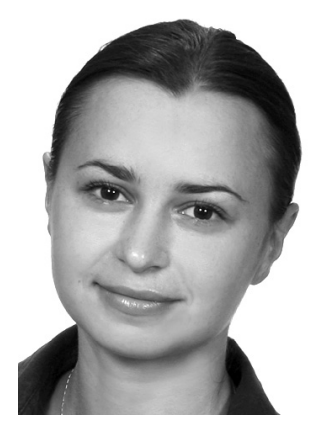

341493, Ростовская обл., п. Персиановкий, ул. Садовая, 78

78 Sadovaya st., 341493, Persianovskiy, Rostov reg., Russia

E-mail: tivano@yandex.ru

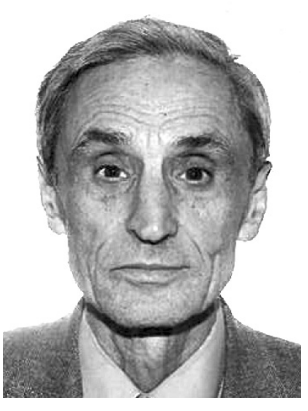

Халас Шандор - доктор технических наук, профессор кафедры электроэнергетики Будапештского университета технологий и экономики.

Halasz Shandor - Doctor of Engineering Sciences, Professor of the Department of Electric Power Engineering, Budapest University of Technology and Economics.

1111, г. Будапешт, Венгрия, Műegyetem rakpart 1-6 Müegyetem rakpart 1-6, 1111, Budapest, Hungary E-mail: info@bme.hu 


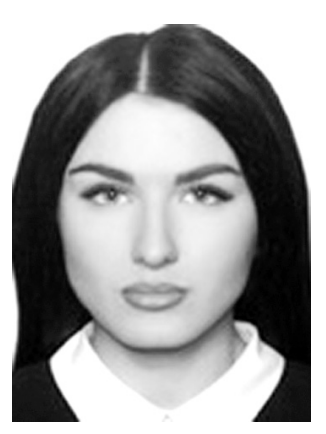

Нардина Анастасия Андреевна - ассистент кафедры «Производственный и инновационный менеджмент» ЮжноРоссийского государственного политехнического университета (НПИ) имени М. И. Платова.

Nardina Anastasia Andreevna - Assistant of the Department «Production and Innovative Management», Platov South Russian State Polytechnic University (NPI).

346428 , г. Новочеркасск, ул. Просвещения, 132

132 Prosveshcheniya st., 346428, Novocherkassk, Russia

E-mail: mozgalevaa@mail.ru 